2013-09

\title{
A social constructivist approach to introducing skills for employment to Foundation Degree students
}

Rutt, L

http://hdl.handle.net/10026.1/4296

10.1080/13596748.2013.819268

Research in Post-Compulsory Education

Informa UK Limited

All content in PEARL is protected by copyright law. Author manuscripts are made available in accordance with publisher policies. Please cite only the published version using the details provided on the item record or document. In the absence of an open licence (e.g. Creative Commons), permissions for further reuse of content should be sought from the publisher or author. 
A social constructivist approach to introducing skills for employment to Foundation Degree Students.

\begin{abstract}
Expectations for higher education providers to produce graduates ready for the workplace has shaped provision, with the introduction of the Foundation Degree, and expectations of an employability component within HE programmes. This paper reports on an intervention for three groups of foundation degree students, which introduces them to ideas of skills for employability. An initial evaluation was followed up two months later exploring the longer-term impact and connections within students' programmes of study, and data were captured from employers and tutors supporting this intervention. In agreement with similar studies, benefits for students were identified; however this research reinforces the challenging nature of the employability agenda, particularly within the context of Foundation Degrees and their dual vocational-academic remit. This paper suggests there is a case to be made for a social constructivist approach within programmes and institutions for promoting awareness and consistency in developing student employability skills.
\end{abstract}

\title{
Introduction
}

The skills agenda and evolution of it within Higher Education (HE) policy in the UK is well documented, from the Dearing (1997) report through to a review by the department for education and skills in 2003, and later the Leitch review of skills (2006). Relatedly, in this time Foundation Degrees (FDs) were launched with a view to promoting vocational HE delivered by HE institutions but also Further Education Colleges (FEC's). With one of the 
main aims of the FD being to improve the level of skilled labour entering the UK workforce (Stanton, 2009), it is appropriate to examine how this is played out within the curriculum and this paper provides focus on one case study where FE college-based FD entrants were introduced to the idea of skills for employment. Despite the emphasis within the policy discourse on skills for employment, research has identified that some students still finish such courses of study without a clear understanding of the value that their course has for their employability (Dismore et al, 2010). Twelve years on from the launch of the FD and the meeting of the ambitious FD recruitment targets (Longhurst, 2010) it is timely to review practice in relation to the skills and employability remit attached to the award. As such, this paper aims to provide an overview of successive policy interventions into the skills for employment agenda, with a particular focus on the awareness of skills for employment of FD students in the HE in FE context. This paper assesses the impact on this of a project which was developed in response to the identification of students lack of awareness of skills for employment (Dismore, Hicks \& Lintern, 2010), framing findings against those from other recent research.

\section{Discourses of Skills for Employment in Higher Education}

In their discussion of the role of skills development in economic health, Yorke and Knight (2006) draw on the Enhancing Student Employability Co-ordination Team's (ESECT) definition of employability, describing it as 'as set of achievements - skills, understandings, and personal attributes - that make graduates more likely to gain employment and be successful in their chosen occupations, which benefits themselves, the workforce, the community and the economy' (ESECT, quoted in Yorke and Knight, 2006: 567). This, they say, is in contrast conceptually and ideologically to key skills which they argue have a narrow, economic rationale, being focused on specific employer identified skills, whereas 
they argue that employability is conceptually broader, connected to ideas of good learning in general and therefore is both more academically palatable and congruent with degree-level learning (Yorke \& Knight, 2006). However, this is a useful distinction to note, both in terms of understanding discourse around skills for employability but also for appreciating the complexities of teaching and researching in this area, and is vital for providing clarity around a diverse set of understandings of these skills.

Atkins (1999) refers to the Dearing Report (1997) as one in a long line which outlines the importance of developing key and transferable skills for employability within the HE setting. However, while a skills focus can be acknowledged as not in itself being new, it is useful to look at the most prominent instances through which this discourse has been perpetuated and re-imagined. This directs us to understand the shifting nature of this agenda, in so much as it has not continued in an identical form, of which Dearing's report is widely regarded to be a key moment in the agenda of skills for employability in HE (e.g. Ducrotoy, 2001; Sleap and Reed, 2006; Wilton, 2008). The Dearing Report (1997) outlines a 20-year vision of the role of HE in UK society. A central message within this is that HE should play a central role in revival of the UK economy through the development of a 'learning society' (Dearing, 1997:23), able to continue to learn and adapt as employment changes and shifts, and connects to the idea of the lifelong learner. As part of this, Dearing (1997) specifies that 'key skills' should be an outcome of any HE programme, these being 'communication, both oral and written, numeracy, the use of communications and information technology and learning how to learn' (point 38). However, while the development of these key skills are linked to broad notions of UK economic health, in which the promotion of (graduate) employment is a significant factor, a short discussion of the need for work experience within HE is the only graduate employability strategy explicitly discussed in the report. 
FDs were one response to the Dearing report, which called for sub-degree level HE as part of the idea of greater connection being made between degree programmes and employment. In Blunkett's speech (Blunkett, 2000) FDs were introduced as two year, sub-degree level qualification, to be primarily taught through the college system but affiliated to partner universities, and built around the idea of equipping students with transferable and key skills perceived as necessary for the workplace to develop UK workforce capacity. Blunkett (2000) makes specific reference to the relationship between the levels of unemployment experienced by graduates following the completion of their degrees and the extent to which they have been encouraged to develop skills for employment, advocating that more skills lead to higher levels of employment. Drawing on insights from employers these skills, stated Blunkett, include: 'communication and team working; problem solving; interpersonal skills; business and customer awareness; and a willingness to continue to learn' (Blunkett, 2000: 58). Blunkett posited that it is these skills which were to be emphasised in FDs, with their strong orientation to 'the employability skills, specialist knowledge and broad understanding needed in the new economy' (Blunkett, 2000). Therefore, FDs were not only fulfilling the need identified by Dearing for sub-degree level HE, but in that locating them in FE colleges, with their perceived stronger connections to local communities and to business, there was greater potential for stronger links to be created between the course programmes and employers (Stanton, 2009), that Dearing had suggested was necessary.

The notion of developing skills for employment through HE was further emphasised in the government White Paper reviewing HE in 2003 (DfES, 2003). This paper particularly brought to focus the notion of FDs being part of the move to lifelong learning, whereby adults will be returning to education throughout their lifetime in order to update and learn 
skills necessary to an evolving innovation and enterprise-focused economy (Stanton, 2009). Further though, the White Paper (DfES, 2003) identifies that FDs may play two differing roles in the HE system, the first of these being that they are an end in their own right, providing individuals with enhanced qualifications, the second role being one step on a 'ladder of progression' whereby the FD learner can then move on to a degree programme in an HEI (DfES, 2003: 44). While the dual purpose of FDs is presented uncritically in the 2003 DfES white paper, it is an issue that has been critically explored since from a number of perspectives (e.g. Greenbank, 2007; Lloyd \& Griffiths, 2008; Winter \& Dismore, 2010).

The final key policy document relevant to this discussion, the Leitch review of skills in 2006 (Leitch, 2006), had a different emphasis to the Dearing report (1997) and DfES white paper (2003), with adult skills in general being the central focus. As such there is little specific mention of FDs or HE, however the broad themes remained in keeping with preceding reports. Interestingly, the definition of 'skills' remains reasonably vague. Leitch (2006) divides them into three main types: "basic skills, primarily of numeracy and literacy; generic skills, such as of communication; and specific skills as necessary for any particular occupation" (Leitch, 2006: 6), however, whilst some of these skills may be imagined, it does little to elaborate other than suggesting that simply more and better education as provided in different forms of qualification are the way of facilitating the growth of a skilled UK adult population. In terms of skills teaching in FDs this contributed little other than to suggest that this is one way in which the desired outcome may be achieved and that FDs should be developed in conjunction with, and response to, employers. The 2004 FD Task Force Report (Department for Education and Skills, 2004) discusses the 'challenges' facing the embedding of the FD within the HE sector. It is noted that the challenge to employers is in their role in 'shaping' HE and establishing greater knowledge of the role of employers within FD 
provision, and a recognition of the value to be gained from establishing links between employers and providers via the means of Sector Skills Councils (Gallacher, Ingram \& Reeve, 2006).

In addition to these agendas, arguments in favour of a focus on the development of skills for employment through HE come from both employers and students. Yorke and Harvey (2005) explained that due to economic pressure on employers in both the public and private sector, there is no longer the level of graduate training in the early stages of employment. Consequently, graduates now need to have a certain understanding of the skills needed in the work environment so that they are able to move directly from their degree programme to a job with full responsibilities and minimal training. Furthermore, Yorke and Harvey (2005) argued that recent decades have seen increasing flows on information and technology in the workplace, and graduates now need to have the skills to be able to manage these. Equally, with UK, students paying increasingly more money for their degree, the concept of HE as an economic transaction has been established with a growing expectation for those undertaking a degree to experience benefits to their employability and capacity to earn money (Gedye et al, 2004; Egerton \& Parry, 2001). This is reflected in the increasing significance of graduate employment statistics for individual universities.

These repeated calls for employability skills development in HE has not passed uncritically though. Boden and Nedeva (2010) maintain that this move is simply part of the on-going neoliberalisation of HE. Their argument is that these attributes are very difficult to quantify and therefore are reduced down to the ways in which they can be, thereby placing an emphasis on student's abilities to 'describe and calculate rather than critically analyse' (Boden and Nedeva, 2010: 50), leading to the production of employees rather than leaders. 
This, they argue, is tied into a degree becoming a means to an economic end rather than more holistic 'voyage of discovery' for those undertaking it. Arguably the very concept of the FD, with the emphasis it has on vocation, magnifies these very aspects of HE policy and practice that Boden and Nedeva (2010) are critiquing, but equally it could be said that introducing vocational education into the HE sphere through FDs introduces these learners to academic critique, therefore enhancing the number of people encountering the skills of critical thinking synonymous with HE. Boud and Symes (2000) chart the development of work-based learning as a force that is gaining momentum, particularly in the institutions with a more "pragmatic outlook" and as a result of contextual economic pressures and the establishment of the link between learning and career aspirations. However the place of FDs in HE still has the potential to be problematic (Stanton, 2009). As the DfES White Paper (2003) identified, FDs are both a highly valid form of learning in their own right, but equally may be used as a point from which learners can move on to undergraduate degrees. Because of their community setting FDs were designed to enhance the local economy, but there is a question as to whether they are really being seen in this way by students and by tutors, or whether these people centrally placed within them view FDs almost solely as a pre-entry for honours degree programmes. There is a sense in which academic drift may take place through FDs in some colleges, where one academic institution tries to imitate the next one up in the hierarchy (Dismore et al, 2010; Garrod \& Macfarlane, 2009) and this demonstrates the extent to which FDs must determine themselves within a difficult position between FE and HE.

Given the complexity and continued relevance of the skills debate we examine the impact of an employability intervention, which sought to introduce new FD students to the notion of skills for employment within their induction period. Drawing on a range of data sources collected we consider students awareness of skills for employment and the connections they 
made between these skills and their FD studies. We frame the outcomes of this research in relation to the wider discourse around skills for employability to consider how a qualification designed to promote synergies between the workplace and academic study is received by students, tutors and employers.

\section{Intervention methodology}

\section{Background framing}

This invention drew on the principles of social constructivism with the aim of developing an awareness of skills for employability among students in the induction week of their FD programmes. The aim of using such an approach was to enable students to develop and construct their own meaning through interaction with peers, course tutors and employers. Rust et al (2005: 232) explain that 'a social constructivist view of learning argues that knowledge is shaped and evolves through increasing participation within different communities of practice.' As such, this approach is about both the engagement of students in practical or active forms of learning, but also the wholehearted adoption of the approach by an institution, whereby all aspects of the programme are thought-through and follow on from each other, rather than just functioning as piecemeal elements of a course (Rust et al., 2005). Given that FDs are grounded in the ethos of employer engagement and work-based learning (Stanton, 2009) we worked with the assumption that these principles would be central to their design and implementation. The implication that learning happens best in a practical situation, echoes the proposals of Knight and Yorke (2003) in their examination of the contexts in which students learn skills for employment. They propose four key ways of students learning these skills, including establishing the perception amongst students of activities as 'sense-making' tasks rather than routine surface 'getting by' learning. Students need to know what they are learning and why, which requires that teachers design learning 
environments that 'help students discover what they afford, what might be learnt, how and why' (Knight and Yorke, 2003: 14, author's emphasis). Their recommendations informed the approach taken in the design of this intervention to introduce students to the skills for employability they would be developing through their FDs.

The entrepreneurial visual planning tool XING resonates with the principles of social constructivism. It has been widely used in careers and employability education throughout England, but to date, there has been limited formal evaluation of its potential pedagogical effectiveness at developing students' employability (http://www.workingknowledge.org.uk/). XING was designed by the Working Knowledge Group to connect further and higher education with the workplace. The activity itself consists of students working in groups over anything from a two hours up to a number of days to develop a business plan to then be presented to a panel of local business people (hereafter referred to as 'experts'). In this process the tool is designed to promote deep learning of skills and attributes relevant to the workplace (e.g. communication, problem solving, team work and time management - all important attributes relevant to the global workplace as advocated in the successive reports reviewed above) (http://www.workingknowledge.org.uk/). It also serves to bring students in direct contact with local employers. The generic nature of the skills introduced renders the event relevant to a range of disciplines and, as such, students from three different subject areas were selected to participate in the day. These subject areas (business, public sector and sports) were broadly representative of the overall FD provision at this FE College.

\section{Data collection}

A two-phase evaluation plan was implemented; phase one involved a questionnaire been administered to the students on the day of the event which took place at the end of the day, 
with a total of 63 responses received. This questionnaire sought to ascertain students' immediate experiences of the day through a series of open and closed questions which explored the extent to which XING had raised their awareness the skills for employment they would be developing through their FDs. In addition, the 15 experts also completed a questionnaire with the aim of exploring their experiences of participating in the day, and evaluating of the effectiveness of the day for the introducing skills they look for in employees.

Phase two took place two months later after which time the students had engaged further with the skills that underpinned the XING event. A reflective questionnaire was used to encourage students to draw connections between skills such as communication, team working and problem solving central to the XING event, which they would have subsequently employed in their studies. In this phase we received no responses from the sports students, therefore we concentrated the analysis upon the 26 responses received from the business and public sector students. The time of administering this questionnaire coincided with a busy period for the students with respect to assessment deadlines and placements, and therefore this is likely to have impacted upon response rates (Cohen et al., 2011). Whilst this does represent an overall reduction in the number of respondents we felt the $43 \%$ response rate across these two subject areas was sufficient to allow inferences to be made (Cohen et al., 2011).

In parallel three tutors (one per subject area) involved in both the XING events and teaching on these FDs, also participated in semi-structured interviews which investigated the way they had integrated the learning from the event into their teaching to support students on-going development of these employment related skills. We took the decision to include the sports 
tutor in this phase as although their students were not included in phase two as we were interested in gaining this tutors' insight to understand their students' experiences with the XING event. In particular the tutors were encouraged to consider the cognitive development of first year FD students and how this may inform their academic and skills development.

\section{Data analysis}

The quantitative data obtained from the closed responses on the phase one questionnaire were numerically coded and analysed using pivot tables. These provided an overview of responses across all programmes and allowed further analysis to identify differences across courses. The qualitative data from the questionnaires and interviews were thematically coded using the constant-comparative approach using the method outlined by Silverman (2005). Themes identified in phase one formed the basis of the subsequent analysis of the phase two data.

\section{Results}

Phase 1 Research: On the day

\section{Student responses}

Data collected following the event indicated that students had their awareness of the importance of developing certain skills for employment raised, although this varied between different skills and from one subject area to another. When asked about specific areas, awareness of certain key skills appears to have been more keenly developed than others. For example, effective communication with fellow students (Figure1) and effective communication with experts (Figure 2) appears to have been most prominent, with up to $73 \%$ and up to $70 \%$ (respectively) of students indicating that their awareness of these skills had been raised by participating in the XING event. Conversely, only up to $58 \%$ of students agreed that their awareness had been raised of the relevance of making informed decisions, 
and this percentage reduced dramatically by course, with the highest percentage being Public Sector students, closely followed by Business students at $54 \%$, but with only $30 \%$ of Sport students identifying this (Figure 3). This would suggest that awareness of skills and types of skills that are being developed can be linked to some degree by cognate area. Although it seemed that XING was broadly good at raising awareness of effective communication skills throughout the three cognate areas, it did not invest resonance with Sports students in terms of their understanding of the more advanced skills relating to making informed decisions.

Figure 1: Perceived impact on the effectiveness of communication with fellow students as part of a team

Figure 2: Perceived impact on the effectiveness of communication with experts in a workrelated setting

Figure 3: Perceived impact on the effectiveness of making informed decisions

Generally student responses focused primarily on individual components of the day, with lunch and winning money being key responses to the question of what they enjoyed most about participation:

"Enjoyable aspects include a competitive atmosphere allowing the group to bond and the chance to win money was very appealing." Public Sector Student 11 Further, mention was made of team work, presentation skills, and communication skills, in response to a question about what they had learnt during the day that may apply to their FD, but there was no indication at this stage of how this may be related to their FDs or of 
developing skills for employability; indicative comments such as these were common responses.

"Today has helped me to work in my group and get to know each other." Public Sector Student 2

"Talking to the people on the course and working with them." Public Sector Student 7 The piecemeal nature of these responses indicates that while an event may be designed to deliver the teaching and learning of particular skills for employment, it is likely that only with appropriate guidance that the broader applicability of these of skills may be fully realised, as this student indicates when asked about what had been learnt during the day:

"Not much as I am on a sports course." Sports Student 1

This is an issue we return to through the analysis of the phase two data.

However, the strength of the social constructivist approach to introducing skills for employment did begin to resonate with some students, leading potentially to the emergence of a deeper understanding of these skills. This was evident in the emotive responses students gave, with feelings of stress, nervousness or frustration at being faced with an unfamiliar task to undertake in a time-limited, competitive situation, or at feeling out of their comfort zone. These feelings were mediated by the enjoyment at working with new people to complete a task and the sense of achievement accompanying this:

"This was a bit daunting at first, however, it was very beneficial as we learnt to get on with other people and also learn there are different ways of undertaking a particular task.” Public Sector Student 4

This indicates that rather than a more passive learning through being lectured about specific skills for employment, the social constructivist approach enables the students to assume more 
responsibility and gain a deeper insight and emotional response when skills are practically tested. This is a strength advocated in the use of this pedagogic approach to support students in developing an awareness of new concepts or ideas (e.g. the work of O'Donovan et al. 2004) which has successfully introduced undergraduates to assessment practices.

\section{Expert responses}

Overall the experts rated the events and their contribution positively, using phrases such as 'refreshing' and 'enjoyable' to describe their experience of been invited to work in a hands on way with undergraduates and encourage them to starting making connections between their programmes of study and the workplace. Indeed the majority identified clear benefits from their limited contributions:

"[...] it opens their eyes to the commercial world and forces them to thinking outside the box." Expert 1;

"Exposure to business concepts at an early stage can only help with their

$$
\text { development." Expert 11; }
$$

They did recognise that it was challenging for new students to be introduced to the ideas of skills for employability in the very early stages of their studies, echoing some of the concerns raised by the students. However, they also acknowledged the importance of promoting such synergies and building on the skills introduced on the day through course curricula and future events:

"[...] I think the activity will benefit them in the coming months as their courses and learning becomes more 'real'. Also it is good to be put on the spot so that you know in future that proper preparation is essential." Expert 13

Despite being busy professionals drawn from a range of local employers they felt that time they had spent contributing to the event was worthwhile, and several were genuinely 
surprised that, given the potential benefits for both employers developing relationships with local education providers, and for students developing an increased awareness of skills for employment, such events were not a regular feature of undergraduate curricula.

\section{Phase 2 Research: Student \& tutor post event reflections}

\section{Student responses}

Returning to the students provided an additional dimension to this evaluation, as not only were they able to consider how they had or had not built on the skills which underpinned the XING event, the analysis also indicated a difference in the ways in which this had been related to their experiences on their FDs, post event. They discussed the skills in three ways, and although not mutually exclusive, they have relevance to our considerations of how tutors can support students developing employability skills. They referred to the XING event as providing either a memorable experience, whereby they made reference to aspects of the day that had stayed with them e.g.

"I also communicated well with fellow students when trying to figure out where we should place the XING cards that were given. " Business Student 6

Others described the event in more reflective terms connecting their experiences on the XING event with their future learning:

"All students have been set a group presentation where we must help each other out in order to receive good marks. So by providing support to your other team members we will do a better job of the presentation as a whole." Business Student 13.

Finally students talked of how they had already applied the skills used in the XING event in their current learning:

"We have a module called working in groups, the XING [event] helped me to develop an understanding of how a successful team works and help to teach me skills such as 
time keeping and communication which are vital to passing this module” Public Sector Student 7.

These quotes are indicative of some of the more positive reflections relating to the value of the day. The references to generic skills that relate to interaction with tutors and experts, teamwork and communication are couched in terms relating to the new situation and environment that they are embarking on as HE students. Although most students do not specifically relate these comments to the wider skills for employability agenda, there is recognition of the value of such events that requires interaction with different groups who will be significant in their new academic experience. For new students this is perhaps the most significant concern at the start of a programme of study (Leese, 2010). The evidence suggests it becomes the role of course tutors to utilise the experience from the event to capture the value that can be used to develop a greater appreciation of the role of their qualification to develop skills for employability. Indeed this is a conclusion reached by Green et al. (2009) and Knight \& Yorke (2003) who identify teaching teams as playing a central role in engaging students with notions of skills for employment. Therefore, using this case study we can begin to further evaluate the role of tutors, and crucially, college managers in addressing employability skills as a pedagogic priority within the curriculum.

In designing and implementing an intervention early on in a student's undergraduate career it is important to be cognisant of their level of academic development, particularly if they are entering HE from non-traditional backgrounds (Leese, 2010). Whilst they may be familiar with the idea of team working and effective communication, their ability to employ these skills on a higher-level may be limited. Indeed, this is evident within the data in relation to the student's consideration of skills such as problem solving and decision-making. Whilst 
these skills were presented in terminology perceived as accessible to new HE students, in both phases of the evaluation they made limited reference to either the application or development of these skills in particular. Within the QAA FD benchmark statements (Quality Assurance Agency, 2010) these are skills students will develop through their studies, however, early on at least they showed limited awareness of these. This can be seen as highlighting the need for clear support and guidance early on from both tutors and the college in order to support students developing the skills integral to their future employability.

\section{Tutor Reponses}

Firstly, in identifying responses from tutors for each of the three FD subject areas, it is possible to see the importance to learning of both embedding the event into the broader setting of the course but also of ensuring the relevance is made apparent to the specific nature of the course. Although skills for employability are recognised as been relatively generic, it appears that they would be better engaged with if more explicitly contextualised to the students (Bridgestock, 2009; Harvey, 2005). Evidence from the second phase of the research supports this argument. Business students engaged with the event to the greatest extent in terms of contextual and cognate understanding of the relevance of the task, but it was Public Sector students who were most encouraged by the tutor to reflect on the relevance of the event to their course in the weeks following. In contrast to this there was little evidence of buy-in from either the Sports students or their tutor due to the perception from both that XING was not as relevant for them and their degree as it was for students on the other participating courses.

"[...] they couldn't see how it related to college, the course or induction. [...] they thought it was more aimed at Business students whereas they didn't see the relevance to it." Sports tutor 
Knight and Yorke (2003) highlighted the importance of institutional buy-in when addressing an agenda such as employability, however this has also been recognised as challenging to obtain (e.g. Cranmer, 2006; Green et al., 2009). In planning this evaluation we assumed a comprehensive buy-in across the participating courses and programme areas given the employment focused and work related nature of FDs. Whilst many tutors contributed on the day the longer-term buy in, which ultimately determined the longevity of impact, was variable, with the day itself seen as part of a wider programme of FD student induction, rather then connecting explicitly to course curricula. This could be addressed with greater support and training of tutors prior to the event and thereby reducing the sense that it had simply been 'brought in' and delivered as a generic enterprise package, somehow separate from the rest of the degree programme - a difficult position to overcome (Cranmer, 2006). Evidence from one of the tutor's suggests that this aspect of constructing the embedding of the activity into the programme is a pivotal to success, leading to further discussions of the ways in which activities such as these could be used to enhance and support the existing curriculum and inform a broader conceptualisation of relevant skills development for employability.

"Staff need to know what it involves so they can sell it to students." Sports tutor

\section{The challenge of reconciling skills for employment with foundation degrees?}

As alluded to in the literature, perhaps a very real problem with addressing the employability skills agenda through the FD lies in the dual nature of the award - with issues such as widening participation (rather than simply increasing it) and the challenges of credit transfer and progression a central concern for policy development (Robertson, 1994a; Robertson, 1994b). Additionally Gibbs (2002) asks the question of 'Who deserves Foundation Degrees'? connecting with the concerns of Boden and Nedeva (2010) that the award in itself can be seen 
as a tool for the enrichment of the economy rather than the individual. Our case study can be seen as reflecting some of these tensions within a relatively small institutional environment. Whilst the need to address the FD qualification benchmark and employability is central to the design of any FD, the ethos of the programme as a ladder to progression in which core academic requirements are met to equip students for Honours progression is an equally important aspect of the award. It is dangerous to generalise from a relatively small study but it can be observed that our three cognate areas seemed to exhibit contrasting approaches to addressing this tension. Interviews with tutors revealed contrasting engagement with employability skills as an overt focus within the curriculum. The Public Sector tutor emphasised certain skills such as teamwork and problem solving as a central to the FD with these skills being developed in every module, as they are vital to the sector. Although the Business and Sports tutors appreciated the importance of skills for employability, they did not highlight any particular skills as sector important and alluded to them as important but not central drivers of the curriculum or ethos of the programme. It was with some regret that this was expressed by one tutor who expressed the view that:

"We focus on formal academic skills and not the soft skills".

They go on to discuss the event and the lack of subsequent tie in with formalised learning, recognising subsequently that

\section{"I think we missed a trick there." Business tutor}

Conversely the Sports tutor identified a focus on teamwork, communication skills and problem solving within the programme and as a central to the curriculum, but also in developing student awareness of the expectations of tutors in terms of academic work and practice. At the same time the tutor expressed the opinion that induction week was not an 
effective time to start this focus on skills development as the students were more attuned to the social aspects of the programme.

“There's a big problem with induction - they just want to go out at night and don't get very actively engaged in induction. Too much skills in induction week is not that effective”. Sports tutor

The contrasting approaches which are exhibited by the three different subject areas demonstrate some interesting cleavages in terms of pedagogic styles for the development of higher level skills and employability. It could be argued that the key differential is approach rather than substance - all tutors identified employability and skills development as important. The crux comes in the way in which this is both conceptualised within the curriculum and operationalised in terms of engaging students as part of a dialogue on the development of skills within their programme of study. Within the Public Sector programme this appears to be a central and overt aspect of the curriculum as opposed to the Business and Sports areas where skills are regarded as additional or complimentary, but without a coherent pedagogic focus or dialogue. This uncertainty is well expressed by the Business tutor:

"Are we just ticking a box or are we actually knowing what specific outcome we are trying to achieve? That's why I am having this problem with what did they get from it. If we knew what we wanted to measure or achieve then maybe we could have a better idea".

This is an interesting position for these tutors to adopt, as although many students develop considerable subject expertise through their degree-level studies, as Gedye et al. (2006) and Hills et al. (2003) highlight, many graduates move away from their area of subject expertise 
following graduation. Therefore the need for students to develop generic skills for employment is clearly central to their future career progression.

Finally, it is notable the focus placed in the tutors comments on their remit for developing students skills for employment, despite the expectations for work-based learning and employer engagement within FDs. Indeed, this expectation needs to be contextualised in term of the responses of the experts - who demonstrated a willingness to engage actively in developing students' employability. Whilst the input of employers needs to be carefully managed alongside their wider professional commitments, there is a sense that they could take a more active role in promoting synergies between the academic and vocational aspects of FDs. In particularly considering the potential for the social constructivist to stimulate dialogue around employment for students, tutors and employers could provide a starting point on which the engagement of employers could be further developed.

\section{Concluding comments}

The expectation has been widely established for graduates to possess a diverse range of skills and be 'employment ready' upon graduating. However, the guidance and support available for HE institutions to address this agenda is variable, and in the example considered here seems to offer distinct cognate variance within what is comparatively a small institutional context where HE provision is facilitated within one HE specific faculty. In many ways the expectations for FD providers to produce graduates who are both ready for progression, if that is their chosen route, or for entry into the workplace (Department for Education and Skills, 2004) makes the translation of the employability agenda increasingly complex. The 'dilemmas and paradoxes' that have arisen from the policy context surrounding the development of the FD (Brown, 2003) can be crystallised to provide some understanding of 
the difficulties on the ground in the pedagogic challenges of FD provision. In bald terms the FD was developed as a qualification for all seasons which needed to address issues of social equity and the higher level technician training needs and appropriate skills development, whilst not placing an excessive burden on the exchequer and maintaining quality and standards.

This evaluation has demonstrated that although early introduction of employability skills can clearly be beneficial, this needs to be explicitly connected with the expectations of both students and course tutors in order to maximise the potential benefits that can be achieved. Equally whilst the generic nature of many interventions to introduced skills for employment can clearly be problematic, they can provide a good foundation on which course tutors can integrate the discipline-specific knowledge and skills. Underlying assumptions that colleges 'are intrinsically good at' working with employers to integrate vocationally based skills development perhaps need revisiting and a more considered appreciation of how these connections can be effectively made within the curriculum. The dual nature of the FD and in particular the subject requirements for progression can arguably be regarded as the most problematic aspect of any programme approval. The employability aspects of the curriculum and the pedagogic approach to the award perhaps deserve a much greater level of consideration if the FD is to stand a chance of meeting the many diverse requirements of this degree. The example used within this paper is argued as a case for the development of such an approach which is rooted in a social constructivist methodology which places appropriate focus on both practitioner and institutional strategies to actively engage students with these requirements.

\section{References}


Atkins, M. J. 1999. Oven-ready and Self-basting: taking stock of employability skills. Teaching in Higher Education 4, no. 2: 267-280

Blunkett, D. 2000. Higher education and the challenges in faces in the $21^{\text {st }}$ century. Speech given at Maritime Greenwich University: http://cms 1.gre.ac.uk/dfee/\#speech (accessed $12^{\text {th }}$ February 2012).

Boden, R. and Nedeva, M. 2010. Employing Discourse: Universities and Graduate 'employability'. Journal of Education Policy 25, no. 1: 37-54

Boud, D. and Symes, C. 2000. Learning for Real: Work-Based Learning in Universities. in Symes, C. and McIntyre, J. (eds.) Working Knowledge: The New Vocationalism and Higher Education. Buckingham: Open University Press.

Bridgstock, R. 2009. The graduate attributes we've overlooked: enhancing graduate employability through career management skills. Higher Education Research and Development 28, no. 1: 31-44.

Brown, R. 2003. New Labour and Higher Education: Dilemmas and Paradoxes. Higher Education Quarterly 57, no. 3: 239-248.

Cohen, L., Manion, L. and Morrison, K. 2011. Research Methods in Education: $7^{\text {th }}$ edition. London: Routledge. 
Cranmer, S. 2006. Enhancing Graduate Employability: best intentions and mixed outcomes. Studies in Higher Education 31, no. 2: 169-184.

Dearing, R. 1997. A Vision for 20 Years: The learning society. Available from: http://www.leeds.ac.uk/educol/ncihe/ [Accessed $12^{\text {th }}$ February 2012].

Department for Education and Skills. 2003. The Future of Higher Education. HMSO: London.

Department for Education and Skills 2004. Foundation Degree Task Force Report to Ministers DfES Nottingham. HMSO: London.

Dismore, H., Hicks, H. and Lintern, M. 2010. The destinations of Foundation degree graduates in the South West of England. Journal of Education and Work 23, no. 5: 451-470.

Ducrotoy, J-P. 2001. Higher Education in Coastal Sciences and Management: Establishing a Partnership Between Education and Industry. Innovations in Education and Teaching International 38, no. 3: 239-250.

Egerton, M. and Parry, G. 2001. Lifelong Debt: Rates of Return to Mature Study. Higher Education Quarterly 55, no.1: 4-27.

Foundation Degree Forward. 2010. The Impact of Foundation Degrees on the Workplace and Students: Research Summary. FDF: Lichfield 
Gallacher, J., Ingram, R. and Reeve, F. 2006. Differing national models of short cycle, workrelated higher education provision in Scotland and England. Glasgow: Centre for Research in Lifelong Learning, Glasgow Caledonian University.

Garrod, N. and Macfarlane, B. 2009. Further, Higher, Better? In Challenging Boundaries ed. N. Garrod and B. Macfarlane, 3-12. Abingdon: Routledge.

Gedye, S., Fender, E. and Chalkley, B. 2004. Students' undergraduate expectations and postgraduate experiences of the value of a degree. Journal of Geography in Higher Education 28, no. 3: 381-396.

Gibbs, P. 2002. Who Deserves Foundation Degrees? Journal of Further and Higher Education 26, no. 3: 197-206.

Golding Lloyd, M.G. and Griffiths, C. 2008. A review of the methods of delivering HE programmes in an FE college and an evaluation of the impact this will have on learning outcomes and student progression. Journal of Further and Higher Education 32, no.1: 15-25.

Green, W., Hammer, S. and Star, C. 2009. Facing up to the challenge: why is it so hard to develop graduate attributes? Higher Education Research and Development 28, no. 1: 17-29.

Greenbank, P. 2007. From foundation to honours degree: the student experience. Education and Training 49, no. 2: 91-102. 
Harvey, L. 2005. Embedding and Integrating Employability. New Directions for Institutional Research 128, no. 1: 13-28.

Hills, J. M., Robertson, G., Walker, R., Adey, M. A. and Nixon, I. 2003. Bridging the Gap between Degree Programme Curricula and Employability through implementation or Workrelated Learning. Teaching in Higher Education 8, no, 2: 211-231.

Knight, P. and Yorke, M. 2003. Employability and Good Learning in Higher Education. Teaching in Higher Education 8, no. 1: 3-16.

Leese, M. 2010. Bridging the gap: supporting student transitions into higher education. Journal of Further and Higher Education 34, no. 2: 239-251.

Leitch, S. 2006. The Leitch Review of Skills. HMSO: London.

Longhurst, D. 2010. Foundation Degrees: 10 Years On. Forward, 20: 3-7.

O’Donovan, B., Price, M. and Rust, C. 2004. Know what I mean? Enhancing student understanding of assessment standards and criteria. Teaching in Higher Education 9, no. 3 : $145-158$.

Quality Assurance Agency. 2010. Foundation Degree qualification benchmark. Gloucester: QAA.

Robertson, D. 1994a. Choosing to change. London: Higher Education Quality Council. 
Robertson, D. 1994b. Proposals for an Associate Degree - the search for the 'missing link' of British higher education. Higher Education Quarterly 48, no.4: 294-322.

Rust, C., O’Donovan, B. and Price, M. 2005. A Social Constructivist Assessment Process Model: How the research literature shows us this could be best practice. Assessment and Evaluation in Higher Education 30, no. 3: 231-240.

Shah, A., Pell, K. and Brooke, P. 2004. Beyond first destinations: Graduate employability survey. Active Learning for Higher Education 5, no. 1: 9-26.

Silverman, D. 2005. Doing Qualitative Research. London, Sage.

Sleap, M. and Reed, H. 2006. Views of sport science graduates regarding work skills developed at university. Teaching in Higher Education 11, no. 1: 47-61.

Stanton, G. 2009. A view from with the English Further Education Sector on the provision of Higher Education: issues of verticality and agency. Higher Education Quarterly 63, no.4: $419-433$

The Working Knowledge Group. http://www.workingknowledge.org.uk/ Accessed $12^{\text {th }}$ February 2012.

Wilton, N. 2008. Business graduates and management jobs: an employability match made in heaven? Journal of Education and Work 21, no. 2: 143-158 
Winter, J. and Dismore, H. 2010. Investigating the experiences of foundation degree students progressing to honours degree: An integrated approach. Journal of Further and Higher Education 34, no.2: 247-264

Yorke, M. and Harvey, L. 2005. Graduate attributes and their development. New Directions for Institutional Research 2005, no. 128: 41-58.

Yorke, M. and Knight, P. 2006. Curricula for economic and social gain. Higher Education 51, no. 4: 565-588. 